\title{
STUDY OF UNCOMPLICATED ADULT INGUINAL HERNIA REPAIR UNDER LOCAL ANAESTHESIA AND SPINAL ANAESTHESIA
}

\author{
M. B. Bagwan', Roshan Chiranjeev², Bhushan Shinde3, Neville Tata4, Parag Kamboj ${ }^{5}$
}

${ }^{1}$ Associate Professor, Department of General Surgery, Krishna Institute of Medical Sciences, Karad.

${ }^{2}$ Resident, Department of General Surgery, Krishna Institute of Medical Sciences, Karad.

${ }^{3}$ Resident, Department of General Surgery, Krishna Institute of Medical Sciences, Karad.

${ }^{4}$ Resident, Department of General Surgery, Krishna Institute of Medical Sciences, Karad.

${ }^{5}$ Resident, Department of General Surgery, Krishna Institute of Medical Sciences, Karad.

\section{ABSTRACT}

\section{BACKGROUND}

This is a comparative study of uncomplicated adult inguinal hernia repair under local anaesthesia and spinal anaesthesia, whereas general anaesthesia requires an experienced anaesthetist with modern equipment and spinal anaesthesia entails post-operative invalidation, while local anaesthesia is easy to administer, simple and effective and causes no post-operative complications. Early ambulation which is hallmark of surgery done under local anaesthesia is a relative term, open to many interpretations. Hence, we have taken up this study to evaluate various aspects of adult inguinal hernia surgery carried out under local anaesthesia and compared it to more conventional methods off surgery under spinal/general anaesthesia.

\section{MATERIALS AND METHODS}

The present study consists of 25 cases of adult uncomplicated inguinal hernia. These patients underwent one day post-operative hospitalisation, surgical treatment as detailed below and results were compared with a control group of 25 cases operated and managed in the more conventional delayed ambulation after post-operative repair. These were recorded on a standard proforma.

\section{RESULTS}

There was significant statistical difference when it came to post-operative analgesia, post-operative complications and element of early ambulation. However, wound healing and recurrence were not affected. It also helped reduce economic burden of both hospital and the patient.

\section{CONCLUSION}

Significant reduction in incidence of post-operative complication without any deleterious effect on wound healing or recurrence even after a 6-month follow-up was established. Early ambulation did not cause any hindrance to wound healing or recurrence. There was significant reduction in terms of cost to the patient and also in reduction of hospital expenses and waiting list.

\section{KEYWORDS}

Adult Inguinal Hernia Repair, Local Anaesthesia, Spinal Anaesthesia.

HOW TO CITE THIS ARTICLE: Bagwan MB, Chiranjeev R, Shinde B, et al. Study of uncomplicated adult inguinal hernia repair under local anaesthesia and spinal anaesthesia. J. Evolution Med. Dent. Sci. 2017;6(24):2038-2041, DOI: $10.14260 /$ Jemds/2017/444

\section{BACKGROUND}

In the late nineteenth and twentieth century after an extensive work on the subject, numerous workers have offered various recommendations in the management of adult uncomplicated inguinal hernia, whereas general anaesthesia requires an experienced anaesthetist with modern equipment and spinal anaesthesia entails postoperative invalidation while local anaesthesia is easy to administer, simple and effective and causes no post-operative complications. Early ambulation which is hallmark of surgery done under local anaesthesia is a relative term, open to many interpretations. Reports of reduction in deep vein thrombosis and lung infections are reduced by early ambulation- Wright Carrol did 16069 hernia repairs over a period of 33 years and

Financial or Other, Competing Interest: None.

Submission 14-02-2017, Peer Review 10-03-2017,

Acceptance 16-03-2017, Published 23-03-2017.

Corresponding Author:

Dr. Roshan Chiranjeev,

Room No. 46, IHR Residents Hostel,

Krishna Institute of Medical Sciences,

Karad-415110, Satara, Maharashtra.

E-mail: roshanchiranjeev@yahoo.co.in

DOI: $10.14260 /$ jemds $/ 2017 / 444$

\section{(c) $($ ) $\$$}

concluded that early ambulation avoids need of bed pan or catheterisation without any post-operative complications. Consensus now favours shorter hospitalisation considering economy and availability of facilities.

The technique of local anaesthesia, if well administered, is sufficient to perform hernia repair. With the above technical and economical considerations, it was planned to carry out a study on adult uncomplicated hernia with the aim of performing the required surgery, preferably under local anaesthesia while encouraging patients for early ambulation.

\section{Aim and Objectives}

1. Comparative study of repair of inguinal hernia under local anaesthesia and spinal anaesthesia.

2. To study the benefits for the patients.

- Cost effectiveness to the patient.

- Hospital stay.

3. To compare complications seen in both the groups.

4. To evaluate effect on wound healing and recurrence after early ambulation.

\section{MATERIALS AND METHODS}

The present randomised case-control comparative study consists of 50 cases of adult uncomplicated inguinal hernia 
observed over 1 year from July 2015 to June 2016; 25 of these patients underwent one day post-operative hospitalisation, surgical treatment as detailed below and results were compared with a control group of 25 cases operated and managed in the more conventional delayed ambulation after post-operative repair. Statistical analysis showed a sample size of 50 to be sufficient for establishing a concrete conclusion. The 25 study Group A were taken up under direct care of this surgical unit, whereas the control Group B cases were taken from other surgical unit not practicing the early ambulation and short hospitalisation in the surgical treatment of uncomplicated adult inguinal hernia.

A detailed clinical evaluation of such case was done including history, physical findings, investigations and operative findings. These were recorded on a standard proforma. All these cases were admitted in the ward one day prior to surgery and they were explained this mode of treatment. There was no restriction as to the type of hernia repair deployed. Factors dictating the selection of any particular technique used in any particular patient were held paramount. In the study group, patients were allowed to move up in the bed immediately after operation. They were allowed to walk after about 4 hours of surgery. The patients were not given routine antibiotics or parenteral analgesics unless specifically indicated, which even was specifically recorded.

\section{Premedication}

30 minutes before operation premedication was given to the patient, consisting of one or more of the following drugs. Injection pentazocine $30 \mathrm{mg}$, injection promethazine $50 \mathrm{mg}$, injection diazepam $10 \mathrm{mg}$, injection atropine $0.5 \mathrm{mg}$ and these were given as required.

\section{Technique of Local Anaesthesia}

$0.25 \%$ of bupivacaine solution was prepared on the spot in a sterilised bowl. The so called solution was used for local infiltration by the technique used by Main-get (1973). Three superficial wheals were raised. The first about 1-11/2" medial to ipsilateral anterior superior iliac spine, the second over the saphenous opening and the third just above and medial to external ring. A 3" long and 23-gauge hypodermic needle was used for anaesthesia solution. The needle was first passed through the first wheal and pierced the skin in a backward and a slightly onward direction until it was left to pierce the muscle and impinges against the bone near anterior superior iliac spine. About $5-10 \mathrm{~mL}$ of solution was injected in this region to block the ilioinguinal, iliohypogastric and branches of last dorsal nerve. The injection was given slightly fanwise and muscle freely infiltrated using the same wheal. The needle was next passed deep to the external oblique aponeurosis and around $5-10 \mathrm{~mL}$ is injected along a line between the first and the third wheal in such a way that the upper aspect of the cord and the undersurface of the aponeurosis were freely bathed in the solution. Another 5-10 $\mathrm{mL}$ was injected along the inner and upper side of the inguinal ligament or its whole length. The base of the scrotum was then held up and through the cord wheal, $5-10 \mathrm{~mL}$ of the solution was run into the root of the scrotum to block the scrotal nerve and 5-10 mL solution was injected in the region of the pubic tubercle behind the cord, which was elevated for this purpose. Through the third wheal, the needle was introduced behind the cord about $5-10 \mathrm{~mL}$ of solution was run into this area to block the spermatic nerve and genital branch of the genitofemoral nerve. Finally, through all three wheals a complete circuminjection of the subcutaneous tissues was performed using $10-15 \mathrm{~mL}$ of anaesthetic solution. After infiltrating the area 5 - 10 minutes were given for obtaining the complete effect. After obtaining the analgesic effect, the standard surgical procedure of herniorrhaphy/plasty were carried out as deemed suitable for each case. The analgesic effect lasted for one to one and half hour in an average case. All the patients in the study group were hospitalised or a maximum of 24 hours postoperatively for observation for any immediate post-operative complications. All patients were followed-up for a period of 3-6 months. Detailed record was maintained in a caserecording proforma.

\section{RESULTS}

The study compromised of an evaluation of surgical repair of 25 uncomplicated inguinal hernias with early ambulation and discharge in comparison to surgery performed for similar uncomplicated adult inguinal hernias in corresponding control group of 25 cases using the more conventional methods under spinal anaesthesia.

The age range observed in this study was 18 - 80 years with maximum number of cases (18) being young adults (20 30 years). Maximum number of cases (17) (34\%) presented within 6 months of occurrence of hernia. In overall incidence, right-sided hernia (33) (66\%) was more than double as compared to left-sided hernia (13) (26\%). In the entire study, we had 4 cases $(8 \%)$ that had bilateral hernia. Indirect inguinal hernia was seen more frequently with an incidence of 23 cases (92\%) in control group, 17 cases $(68 \%)$ in the study group, a total of 40 cases $(80 \%)$. In this study, there was no case of combined direct and indirect hernia. Overall, incomplete inguinal hernia was seen in 43 patients (86\%) and complete hernia was seen in 7 patients $(14 \%)$. The commonest repair deployed in the management of inguinal hernia was Lichtenstein repair, 23 cases (92\%) in control group and 15 cases $(60 \%)$ in the study group. In any case, operative time was calculated from incision till application of skin stitches. The average operative time for both control and study group was almost similar, i.e. 56.8 minutes for control group and 52.8 minutes for study group.

A comparison of confinement in the bed following surgery was undertaken with regard to post-operative ambulation in both control and study group. The 25 cases operated under spinal anaesthesia or supplemented with ketamine were strictly confined to bed for $24-26$ hours, majority of the patients (22) (88\%) could ambulate within 49 - 72 hours and 3 patients $(12 \%)$ could walk after 72 hours. In the study group, majority of the patients (20) (80\%) could be ambulated within 5 - 12 hours, 1 could be ambulated within 4 hours, 2 cases could ambulate within $25-4$ hours and the remaining 2 cases could ambulate within $49-72$ hours (Chi square- 42.667 , $P$ value $<0.0001$, significant association). The control group cases having surgery performed under spinal anaesthesia had to be kept fasting for $4-12$ hours and was given intravenous fluids for supplementation.

In the control group, immediate post-operative complications such as vomiting, headache, retention of urine 
requiring catheterisation and hypotension was seen in 3 cases, 3 cases, 3 cases and 1 case respectively whereas none of the patients in the study group had these complications (Chi square- $11.000, \mathrm{P}$ value- 0.0266 , significant association). In the control group, injectable analgesics were given for 12 hours followed by oral analgesics, whereas in the study group only oral analgesics were given and effect recorded as complete or incomplete relief (Chi square- 45.731, $\mathrm{P}$ value $<0.0001$ ). Average duration of wound healing was similar in both groups, control group- 7.76 days and in the study group7.26 days. Post-operative wound complications such as haematoma, seroma and wound sepsis was seen in both groups with no significant effect of early ambulation on the wound healing (Chi square- 2, P value- 0.3679 ). Majority of the cases had follow-up of 6 months. There was no recurrence of hernia in control group as well as in study group during this period.

The average post-operative stay in the hospital of the control group was 103 hours, whereas in the study group 12 cases (48\%) were ambulatory and fit to be discharged within 24 hours post-operatively (Chi-square- 35.578, $\mathrm{P}$ value$<0.0001$, significantly associated); 20 patients of the study group had mild pain and ambulation was easy and only 4 patients (16\%) had moderate pain which was acceptable; 24 patients (96\%) would accept this mode of technique or surgical repair of inguinal hernia if they had to be operated under similar circumstances again. The statistical method included chi-square test and $\mathrm{P}$ value to compare the results.

\begin{tabular}{|c|c|c|c|c|}
\hline Post-Operative & \multicolumn{2}{|c|}{ Control Group } & \multicolumn{2}{c|}{ Study Group } \\
\cline { 2 - 5 } Ambulation & No. & $\mathbf{\%}$ & No. & $\mathbf{\%}$ \\
\hline 1 - 4 Hours & 0 & $0 \%$ & 1 & $4 \%$ \\
\hline 5 - 12 Hours & 0 & $0 \%$ & 20 & $80 \%$ \\
\hline 25 - 48 Hours & 0 & $0 \%$ & 2 & $8 \%$ \\
\hline $49-72$ Hours & 22 & $88 \%$ & 2 & $8 \%$ \\
\hline After 72 Hours & 3 & $12 \%$ & 0 & $0 \%$ \\
\hline Total & $\mathbf{2 5}$ & $\mathbf{1 0 0 \%}$ & $\mathbf{2 5}$ & $\mathbf{1 0 0 \%}$ \\
\hline Table 1. Post-Operative Ambulation &
\end{tabular}

Chi Square value- 42.667

$P$ Value $<0.0001$

\begin{tabular}{|c|c|c|c|c|}
\hline \multirow{2}{*}{ Complications } & \multicolumn{2}{|c|}{ Control Group } & \multicolumn{2}{c|}{ Study Group } \\
\cline { 2 - 5 } & No. & $\mathbf{\%}$ & No. & $\mathbf{\%}$ \\
\hline Vomiting & 3 & $12 \%$ & 0 & $0 \%$ \\
\hline Headache & 3 & $12 \%$ & 0 & $0 \%$ \\
\hline Hypotension & 1 & $4 \%$ & 0 & $0 \%$ \\
\hline $\begin{array}{c}\text { Retention of Urine } \\
\text { and Catheterisation }\end{array}$ & 3 & $12 \%$ & 0 & $0 \%$ \\
\hline \multicolumn{2}{|c|}{ Table 2. Immediate Post-Operative Complications } \\
\hline
\end{tabular}

Chi square value- 11.000

$P$ value $<0.0266$

\begin{tabular}{|c|c|c|c|c|}
\hline \multirow{2}{*}{ Analgesics } & \multicolumn{2}{|c|}{ Control Group } & \multicolumn{2}{c|}{ Study Group } \\
\cline { 2 - 5 } & No. & $\mathbf{\%}$ & No. & \% \\
\hline Injectable & 25 & $100 \%$ & 2 & $8 \%$ \\
\hline Oral & 0 & $0 \%$ & 23 & $92 \%$ \\
\hline \multirow{2}{*}{ Relief } & Control Group & Study Group \\
\cline { 2 - 5 } & No & $\%$ & No & \% \\
\hline Incomplete & 4 & $16 \%$ & 2 & $8 \%$ \\
\hline Complete & 21 & $84 \%$ & 23 & $92 \%$ \\
\hline Total & $\mathbf{2 5}$ & $\mathbf{1 0 0} \%$ & $\mathbf{2 5}$ & $\mathbf{1 0 0 \%}$ \\
\hline \multicolumn{4}{|c}{ Table 3. Requirement of Analgesic } \\
\hline
\end{tabular}

Chi Square value- 45.731

$P$ value $<0.0001$

\begin{tabular}{|c|c|c|c|c|}
\hline & \multicolumn{2}{|c|}{ Control Group } & \multicolumn{2}{c|}{ Study Group } \\
\cline { 2 - 5 } & No. & $\mathbf{\%}$ & No. & $\mathbf{\%}$ \\
\hline Haematoma & 1 & $4 \%$ & 0 & $0 \%$ \\
\hline Seroma & 2 & $8 \%$ & 2 & $8 \%$ \\
\hline Wound Sepsis & 0 & $0 \%$ & 1 & $4 \%$ \\
\hline Total & $\mathbf{3}$ & $\mathbf{1 2 \%}$ & $\mathbf{3}$ & $\mathbf{1 2 \%}$ \\
\hline $\begin{array}{l}\text { Average duration } \\
\text { of Wound Healing }\end{array}$ & \multicolumn{2}{|c|}{7.76 Days } & \multicolumn{2}{|c|}{7.26 Days } \\
\hline \multicolumn{3}{|c|}{ Table 4. Post-Operative Complications } \\
\hline
\end{tabular}

Chi Square value- 2

P value $<0.3679$

\begin{tabular}{|c|c|c|c|c|}
\hline Post-Operative & \multicolumn{2}{|c|}{ Control Group } & Study Group \\
\cline { 2 - 5 } Stay in Hours & No & $\mathbf{\%}$ & No & $\%$ \\
\hline$<12$ & 0 & $0 \%$ & 2 & $8 \%$ \\
\hline $13-24$ & 0 & $0 \%$ & 10 & $40 \%$ \\
\hline $25-36$ & 0 & $0 \%$ & 6 & $24 \%$ \\
\hline $37-48$ & 1 & $4 \%$ & 4 & $16 \%$ \\
\hline $49-72$ & 3 & $12 \%$ & 1 & $4 \%$ \\
\hline $73-96$ & 7 & $28 \%$ & 2 & $8 \%$ \\
\hline $97-120$ & 2 & $8 \%$ & 0 & $0 \%$ \\
\hline $121-144$ & 2 & $8 \%$ & 0 & $0 \%$ \\
\hline$>145$ & 10 & $40 \%$ & 0 & $0 \%$ \\
\hline Total & $\mathbf{2 5}$ & $\mathbf{1 0 0 \%}$ & $\mathbf{2 5}$ & $\mathbf{1 0 0 \%}$ \\
\hline Table 5. Post-Operative Hospital Stay \\
\hline
\end{tabular}

Chi square value- 35.578

$P$ value $<0.0001$

\begin{tabular}{|c|c|c|c|c|}
\hline \begin{tabular}{|c|} 
Sl. \\
No.
\end{tabular} & Questionnaire & Answers & Cases & $\%$ \\
\hline 1 & Operative Pain & $\begin{array}{c}\text { No Pain } \\
\text { Mild Pain } \\
\text { Moderate Pain }\end{array}$ & $\begin{array}{c}- \\
20 \\
4\end{array}$ & $\begin{array}{c}- \\
80 \\
16\end{array}$ \\
\hline 2 & $\begin{array}{c}\text { Post-Operative } \\
\text { Analgesia }\end{array}$ & $\begin{array}{c}\text { Satisfactory } \\
\text { Unsatisfactory }\end{array}$ & $\begin{array}{c}20 \\
5\end{array}$ & $\begin{array}{l}80 \\
20\end{array}$ \\
\hline 3 & Ambulation & $\begin{array}{c}\text { Easy } \\
\text { Tolerable } \\
\text { Difficult }\end{array}$ & $\begin{array}{c}20 \\
- \\
5\end{array}$ & $\begin{array}{c}80 \\
- \\
20\end{array}$ \\
\hline 4 & $\begin{array}{l}\text { Problem at Home- } \\
\text { Pain/Discomfort }\end{array}$ & $\begin{array}{c}\text { No Discomfort } \\
\text { Mild } \\
\text { (Acceptable) }\end{array}$ & $\begin{array}{c}20 \\
5\end{array}$ & $\begin{array}{l}80 \\
20\end{array}$ \\
\hline 5 & $\begin{array}{c}\text { Overall Opinion Regarding } \\
\text { Acceptability } \\
\text { of this Technique or } \\
\text { will the Patient like } \\
\text { to be Operated upon } \\
\text { again under Similar } \\
\text { Circumstances if Need Arise }\end{array}$ & $\begin{array}{l}\text { Yes } \\
\text { No }\end{array}$ & $\begin{array}{l}24 \\
1\end{array}$ & 96 \\
\hline \multicolumn{5}{|c|}{ Table 6. Patient response (Study Group) } \\
\hline
\end{tabular}

\section{DISCUSSION}

In the present study, we found that early ambulation was much more feasible in patients operated under local anaesthesia as compared to patients operated under spinal anaesthesia. Farquharson in his series of 485 herniorrhapies under local anaesthesia had his patients walk to and from the operation table with absolutely no deleterious effects. ${ }^{1} \mathrm{P}$ Sanjay and A Woodward performed 577 hernia repairs, of these 369 repairs were performed under local anaesthesia 
and 208 under general anaesthesia. Day-care repair was achieved in 400 cases $(70 \%)$. The day-care rates were significantly higher under local anaesthesia compared to general anaesthesia. Also, patients under local anaesthesia had lower post-operative requirements and lower incidence of urinary retention compared with the spinal/general anaesthesia group. ${ }^{2}$ The local anaesthesia does not require the services of the anaesthetist or any costly equipment. The repair of groin hernias employing local anaesthesia has proved cost effective. ${ }^{3}$ Local anaesthesia not only reduces the waiting list, it also reduces the economic burden of the hospital and the patient. Local anaesthesia has been found adequate for any type of reconstructive repair, whichever one is chosen to be undertaken. Any discomfort which the patient may experience is due to dragging on the peritoneum, while neck of the sack is cleared. ${ }^{4}$ Advanced age itself is no bar for this method. On the contrary it is fairly useful, as it keeps them away from the stress of spinal/general anaesthesia.

The results obtained clearly shows that there is no increase in incidence of wound complications when the patient is made ambulatory at an early stage. These observations are similar to the observation made by Farquharson. ${ }^{1}$ John Hunter described rest as a most powerful aid which the surgeons can bring to the disordered tissue and Hugh Owen Thomas stated that rest must be enforced, uninterrupted and prolonged. ${ }^{1}$ The conventional method of delayed ambulation is based on this belief, but it is certainly open to question, whatever the patient may fear, wound does not disrupt as a result of early ambulation. Early ambulation also reduces the complications such as deep vein thrombosis and pulmonary complications. As long as the patient is confined to the bed, respiration remains shallow and vital capacity is reduced. 5 The fear that immediate mobilisation following repair might disrupt some stitches and so lead to higher rate of recurrence is unfounded and this represents a fault in operative technique and not on ambulation. ${ }^{6}$ It is known that $70 \%$ of intact tissue strength is achieved immediately in wounds, provided that non-absorbable sutures are used and this is the same after 2 months of healing. ${ }^{7}$ Palumbo and Sharpe in randomised study of 3155 patients demonstrated no difference in recurrence rate after hernia repair, whether the patients were mobilised after operation, between $3^{\text {rd }}$ or $9^{\text {th }}$ day and $10^{\text {th }}$ day. ${ }^{6}$

As far as the reaction and acceptability of the patient to this mode of treatment is concerned, a set of questions was put to all patients. There was easy acceptability by the patients and appreciation of the method. Shorter stay is much more economical to the patient. Coe and Rockwell have compared the cost of outpatient versus inpatient repair of inguinal hernia. They have effected a net saving of Dollar 502 to 700 per patient.8,9 In our study because of early ambulation and short stay, there was a net saving of Rs. 7000 per patient and by reducing the average post-operative hospital stay from 4.29 days to a single day, the expenditure and work load on the hospital staff was reduced considerably, thereby decreasing the waiting list.

\section{CONCLUSION}

Early ambulation has no deleterious effects on wound healing. It reduces the incidence of complications uplift the patient's morale and in every way his recovery. Early ambulation along with early discharge of patient from hospital in no ways affects the repair of inguinal hernia and does not increase the recurrence rate. Also, there is reduction in morbidity and in incidence of complications.

The introduction of "short-study surgery" not only relieves hospital waiting list, but also represents an economic advantage and has certain social benefits for the patient. Early mobilisation should be encouraged, but it is wiser to allow the protective sensation to return before mobilisation. We prefer "short stay surgery" as compared to "day care surgery" in the repair of inguinal hernia.

Inguinal hernioplasty, no matter how extensive can be carried out with complete safety using local anaesthesia. Local anaesthesia is a preferable option than spinal anaesthesia to practice early ambulation and short-care surgery. We have demonstrated good patient acceptability and significant decrease in the financial costs with repair of inguinal hernia in ambulatory patients under local anaesthesia.

\section{REFERENCES}

[1] Farquharson EL. Early ambulation; with special reference to herniorrhaphy as an outpatient procedure. Lancet 1995;269(6889):517-9.

[2] Sanjay P, Woodward A. Inguinal hernia repair: local or general anaesthesia? Ann $\mathrm{R}$ Coll Surg Engl 2007;89(5):497-503.

[3] Paul A, Troidl H, Williams JI, et al. Randomized trial of modified Bassini versus Shouldice inguinal hernia repair. British journal of surgery 1994;81(10):1531-4.

[4] Doran FS, White M, Drury M. The scope of safety of short stay surgery in the treatment of groin herniae and varicose veins. A report on 705 cases. Br J Surg 1972;59(5):333-9.

[5] Churchill ED, McNeil D. The reduction in vital capacity following operation. Surg Gynecol Obstet 1927;44(6):483-8.

[6] Britton JB, Morris PJ. Local anesthetic hernia repair. An analysis of recurrence. Surg Clinics of North America 1984;64(2):245-55.

[7] Lichtenstein IL. Hernia repair without disability: a surgical atlas illustrating the anatomy, technique, and physiologic rationale of the one-day hernia. CV Mosby 1970.

[8] Coe RC. Changing methods best way to cut costs. Am Med News 1981;24:5.

[9] Ozgun H, Kurt MN, Kurt I, et al. Comparison of local, spinal and general anaesthesia for inguinal herniorrhaphy. Eur J Surg 2002;168(8-9):455-9. 